\title{
Effect of Seasonal Variation on Mycorrhizal Fungi Associated with Medicinal Plants in Central Himalayan Region of India
}

\author{
Supriya Gaur, Purshotam Kaushik
}

Department of Botany and Microbiology, Gurukul Kangri University, Haridwar, India.

Email: supriya.gaur@rediffmail.com

Received January $17^{\text {th }}, 2011$; revised February $25^{\text {th }}$, 2011; accepted March $20^{\text {th }}, 2011$

\begin{abstract}
This research paper assesses the effect of seasonal variation on mycorrhizal fungi. Based on the richness of medicinal plants in Himalayan region, this research work considered three medicinal plants i.e. Catharanthus roseus Linn., Ocimum spp. and Asparagus racemosus Willd. The study was conducted at five districts of Uttarakhand state of India viz. Pauri Garhwal, Haridwar, Dehradun, Udham Singh Nagar and Almora. To account for seasonal variations, soil and root samples were collected in months of Jan-Feb, May-June and Sep-Oct from year 2006 to 2008. Furthermore, the study was directed to collect information about the distribution of VAM fungi in the medicinal plants in relation to spore population. This research work evaluated and analyzed the effect of temperature, altitude and seasonal conditions. The undisturbed natural vegetations revealed maximum spore numbers followed by cultivated and non-cultivated regions. Similarly, root colonization by VAM fungi was observed at higher levels in natural vegetations and cultivated sites in comparison to non-cultivated lands. The monthly and seasonal temperature varied and had considerable effect on VAM fungal population. The data obtained in the present study undoubtedly indicate that the seasonal variation in VAM fungi is significant with few exceptions. VAM fungi in medicinal plants differ in the manner and extent with which root colonization rate occurs and also differ in their capacity to form propagules. Most of the study reveals that host plant had much more effect on spore population. Number of spores also varied with the growing season of the host plant. During the present study most of the sites showed a general increase in spore number from Sep-Oct to Jan-Feb.
\end{abstract}

Keywords: Vesicular Arbuscular Mycorrhiza; Medicinal Plants; Seasonal Variation; Himalaya

\section{Introduction}

Mycorrhiza is a symbiotic mutualistic relationship between special soil fungi and fine plant roots; it is neither the fungus nor the root, but rather the structure formed from these two partners. Since the association is mutualistic, both organisms benefit from the association. The fungus receives carbohydrates (sugars) and growth factors from the plant, which in turn receives many benefits, including increased nutrient absorption. In this association, the fungus takes over the role of the plant's root hairs and acts as an extension of the root system [1]. The potential for manipulating mycorrhizal associations to increase productivity in plantation forestry, or plant establishment during ecosystem recovery after severe disturbance, are the focus of major research initiatives. There is also much interest in their potential utilization in medicinal, agricultural and horticultural crops. Vesicular Arbuscular Mycorrhiza (VAM) is present in most medicinal plants, agronomic and vegetable crops. This type is char- acterized by the presence of arbuscules in the region of the root cortex; vesicle may or may not be present; and they function as reserve organs and also for fungal multiplication. Vesicular-arbuscular mycorrhizas (VAM) and arbuscular mycorrhizas are recognized as most common type of mycorrhizae with diverse host range [2].

The Himalayan state of Uttarakhand is very rich in medicinal and aromatic plants [3]. The medicinal plants in the region occur naturally and most of them propagate vegetatively by underground rhizomes, stems and bulbs or corms. This herbal wealth is being used not only by developing countries but also by developed countries for their health care systems. A bulk of our rural population relies on drug resources of plant origin. Locally collected plants are sold, where they are exploited commercially for preparation of medicines.

Three medicinal plants viz. Sadabahar (Catharanthus roseus Linn.), Tulsi (Ocimum spp.) and Shatavar (Asparagus racemosus Willd.) were considered for the pre- 
sent research work. Sadabahar, Tulsi and Shatavar were identified for research purpose since the medicinal uses of these plants are tremendous. The roots of Sadabahar are sedative, tranquiliser, stomachic and are used as tonic. The leaves of Sadabahar in form of an infusion are administered in menorrhagia and their juice is good for wasp-stings. It is also used as remedy for diabetes. An extract from the Sadabahar plant has shown growth inhibitory effect in certain human tumours. The plant of Tulsi is considered expectorant, stomachic, diuretic, antiseptic and cardiac stimulant and its decoction is used in catarrh, croup and bronchitis. The roots of Shatavar are refrigerant, demulcent, diuretic, aphrodisiac, antiseptic, antidiarrhoeal, antidysentric and galactagogue [3]. The medicinal value of these plants has been utilized since Vedic period [4,5]. Since these plants have great medicinal values, this research was carried out to study their associated VAM fungi and various factors which affected their growth.

Generally, vesicular arbuscular mycorrhizae form in temperatures ranging between $18^{\circ} \mathrm{C}$ and $40^{\circ} \mathrm{C}$ with the optimum for most fungal host species near $30^{\circ} \mathrm{C}$. The optimal range for the intact symbiosis depends on the temperatures controlling fungal germination, photosynthesis and carbon flow to roots. However, the influence of temperature on arbuscular mycorrhizal plants is variable and appears related to the exact fungal host species combination as well as the developmental stage of the plant. Spores of VAM fungi differ in their optimum germination temperatures $[6,7]$. Soil temperature along with soil moisture exerts a major influence on mycorrhizal colonization of plants [8].

\section{Material and Method}

The present research work investigates rhizosphere soil samples and plant samples of three medicinal plant species. The samples were collected from different habitats of Uttarakhand state of India. The study was started in December, 2005 and soil samples were initially collected during January-February 2006. After initial collection, the samples were collected regularly at an interval of 2 3 months.

\subsection{Sites}

The soil samples for the present investigation were collected from different parts of Uttarakhand state viz. Pauri Garhwal, Haridwar, Dehradun, Almora and Udham Singh Nagar. The collection sites were chosen such that the samples represented the complete state in terms of its major division of Garhwal and Kumaon region; and the different height of Himalayan ranges.

The collection sites chosen from district Pauri were
Dhari, Srinagar, Srikot, Pauri, Ghurdauri, Khandusain, Kotdwar, Safdarkhal, Minthi, Doggada, Kaliasaur, Satpuli, Lansdown, Buvakhal, Jwalpadevi, Patisain, Gumkhal, Dandapani, Kyunkaleshwar, Kandolia, Nagdev, Dhumakot, Nainidanda, Kalagarh, Chilla and Binsar. The sites chosen from district Haridwar were Bhagwanpur, Laksar, Jwalapur, Khanpur, Roorkee, Manglaur, Bahadrabad, Narsan, Patanjali, Kankhal, Sultanpur, Pathri, Jhabreda, Landora and Pirankaliyar. The sites in Dehradun district were Tapovan, Mussourie, Rishikesh, Chakrata, Dakpathar, Sahastradhara, Jollygrant, Ballupur, Tigerfall, Khoonigarh, Lakhamandal, Rajpur, Raipur, Pathribagh, Lachhiwala, Kalsi, Anarwala, Sinola, Kisanpur, Doiwala and Forest Research Institute (FRI). The collection sites in Almora district were Bhanoli, Jainti, Someshwar, Chaukutia, Bhikiasain, Sult, Bhatraujkhan, Marchula, Manila, Dunagiri, Pandhuka, Majkhali, Binsar, Jalna, Sheraghat, Takula, Gananath, Kaparkhan, Binta, Gangolihat, Katpuriya, Sitlakhet, Upal, Gwalakhot, KosiKatarmal, Kausani, Jageshwar, Ranikhet and Dwarahat. The collection sites in district Udham Singh Nagar were Khatima, Rudrapur, Pantnagar, Sitarganj, Kichha, Gadarpur, Bazpur, Kashipur, Jaspur, Tanakpur, Nanakmatta, Doraha and Negigarhi.

Fine roots of plants along with soil samples were collected from these sites. The roots were preserved and later on stained for determination of percent mycorrhizal colonization. Sterlized polythene bags were taken to the site for soil sample collection. Rhizosphere soil samples were collected at the depth of $4-16 \mathrm{~cm}$. These samples were naturally air dried for further experimental analysis.

\subsection{Isolation of VAM Spores from Soil}

Various techniques are used to recover VAM propagules from soil [9]. There are primarily two types of techniques viz. 1) Wet sieving and decanting technique; 2) Density gradient technique. The most basic of these is wet sieving and decanting technique. This technique is used to remove the clay and sand fractions of the soil while retaining spores and other similar sized soil and organic matter particles on sieves of various diameters. On the other hand, Density gradient centrifugation is also now commonly used technique for extraction of VAM spores. In this research work, wet sieving and decanting technique was used for extraction of spores.

\subsection{Qualitative Analysis of VAM Fungi}

The VAM fungal spores are analyzed qualitatively by identifying them for their genera and species. The VAM fungal spores collected on filter paper (Whatman filter paper No. 1) after wet sieving and decanting technique were observed under Stereoscopic binocular. These spores 
were picked through needle and mounted in lactophenol on slide. As an alternative, Polyvinyl lactic acid was also used as mounting medium. All slides with spores on mounting medium were observed cautiously under high power research microscope for isolation into genera and followed by species identification.

\subsection{Identification of VAM Spores}

VAM spores were identified using standard monographs given by Hall and Fish [10]; Hall [11,12], Gerdemann and Trappe [13]; Schenck and Perez [14]; and INVAM (http://www.invam.caf.wvu.edu).

\subsection{Moisture Content of Soil}

For determination of moisture content of soil, oven drying method [15] was used. 5 - $10 \mathrm{~g}$ of soil was immediately weighed and kept in the hot air oven at $105^{\circ} \mathrm{C}$ $110^{\circ} \mathrm{C}$ for $24 \mathrm{Hrs}$. The amount of water lost, which is the water content of the sample is calculated as follows:

$$
\begin{aligned}
\mathrm{H}_{2} \mathrm{O} \text { lost }= & \text { Weight of moist soil } \\
& - \text { Weight of oven dry soil }
\end{aligned}
$$

The moisture in the soil $(\% \mathrm{w} / \mathrm{w})$ was calculated.

\section{Results}

VAM fungi are well distributed throughout Uttarakhand. Maximum numbers of spores were isolated from Dehradun district followed by Udham Singh Nagar, Haridwar, Pauri and Almora. Soil samples collected from hilly terrain showed fewer VAM spores. The occurrence of spores at higher altitudes (above $1700 \mathrm{~m}$ ) was qualitatively and quantitatively inferior as compared to regions at lower altitude regions.

Seasonal variation significantly effects the population of spores. Three different duration of season in a year from 2006 to 2008 were chosen with each part of the season spanning for an interval of two months i.e. JanFeb, May-June and Sep-Oct. Generally, spore count was observed to be on higher side during Jan-Feb and SepOct, however, at high altitude (above $1500 \mathrm{~m}$ ) the spore count was higher during May-June. During the period of higher temperature i.e. May-June, the spore count reduced, where as in the months of Jan-Feb and Sep-Oct, VAM spore population increased.

Soil samples collected from cultivated habitats of Dehradun, Pantnagar, Haridwar, Pauri and Almora had larger number of spores in comparison to un-cultivated sites such as Kyunkaleshwar and Dehradun forests. The study reveals that VAM fungal spores are in abundance in cultivated soil as compared to non-cultivated soils. Species richness of VAM fungi was highest at Dehradun district followed by Haridwar, Udham Singh Nagar, Pauri and Almora.

During 2006-2008 the effect of seasonal variations on the distribution of VAM fungi was determined at fifteen sites. The results that were obtained and analyzed revealed that there is a definite fluctuation in number of spores at some sites. Maximum numbers of spores were isolated from site $\mathrm{M}$ and $\mathrm{H}$ throughout the study period (Table 1). From site $\mathrm{M}$ and $\mathrm{H}$ the soil samples were collected from rhizosphere of Tulsi, Sadabahar and Satavar. Glomus fasciculatum species were isolated dominantly from site $\mathrm{M}$ and $\mathrm{H}$. Spores of Glomus aggregatum, Glomus mosseae, Glomus macrocarpum, Gigaspora margarita and Acaulaspora laevis were also observed. The spores of VAM fungi for all plants were isolated comparatively less in May-June (Figures 2, 5 and $\mathbf{8}$ ) as compared to Jan-Feb (Figures 1, 4 and 7) and Sep-Oct (Figures 3,6 and 9 ).

The rhizosphere soil in Catharanthus roseus yielded maximum numbers of spores at sites A, B, D, F, G, L, M and O. Glomus fasciculatum and Glomus aggregatum were found as dominant VAM species. The spores of other VAM fungi such as Glomus claroideum, Glomus mosseae and Glomus monosporum were also observed. At sites A, B and L spore count was maximum in SepOct, however, at other sites like D, F, G, M and O spore count was minimum in May-June.

The maximum number of spores in rhizosphere soil of Ocimum species were obtained at sites F, G, H, I, K, M and $\mathrm{N}$. In contrast to this observation, the minimum numbers were isolated at sites $\mathrm{C}$ and $\mathrm{J}$. The isolated spores of Glomus aggregatum and Glomus fasciculatum

Table 1. List of collection sites and respective soil type.

\begin{tabular}{cccc}
\hline S. No. & Collection site & District & Soil type \\
\hline A & Lansdown & Pauri & Sandy loam \\
B & Patisain & Pauri & Sandy loam \\
C & Kyunkaleshwar & Pauri & Sandy loam \\
D & Manglaur & Haridwar & Clay \\
E & Narsan & Haridwar & Clay \\
F & Patanjali & Haridwar & Loam \\
G & Rishikesh & Dehradun & Sandy loam \\
H & Dakpathar & Dehradun & Sandy loam \\
I & Tigerfall & Dehradun & Loam \\
J & Someshwar & Almora & Sandy loam \\
K & Jalna & Almora & Sandy loam \\
L & Gangolihat & Almora & Sandy loam \\
M & Pantnagar & Udham Singh Nagar & Loam \\
N & Gadarpur & Udham Singh Nagar & Clay \\
O & Nanakmatta & Udham Singh Nagar & Clay \\
\hline
\end{tabular}




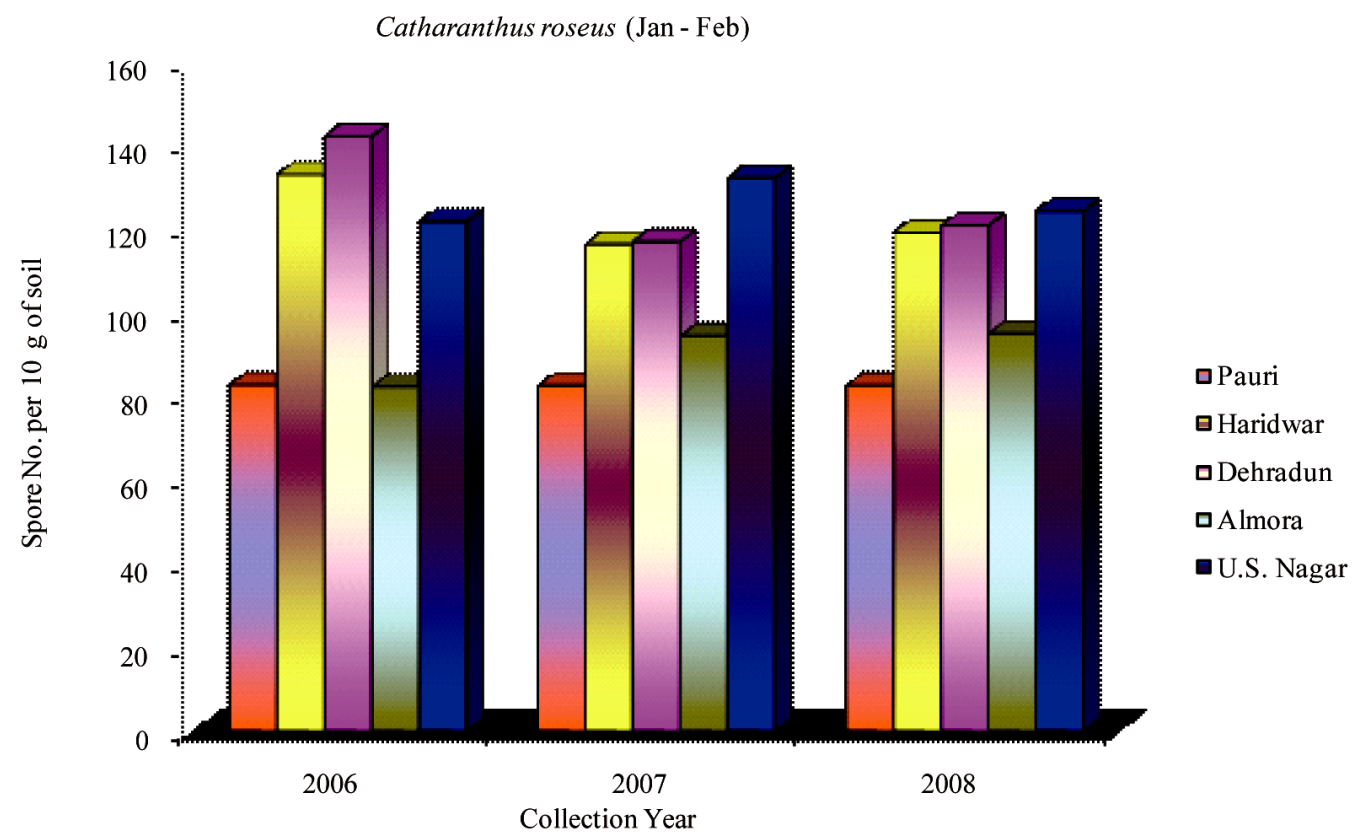

Figure 1. Average number of VAM fungal spores isolated from the soil samples of Catharanthus roseus from different districts in Uttarakhand state during the months of January and February from year 2006 to 2008.

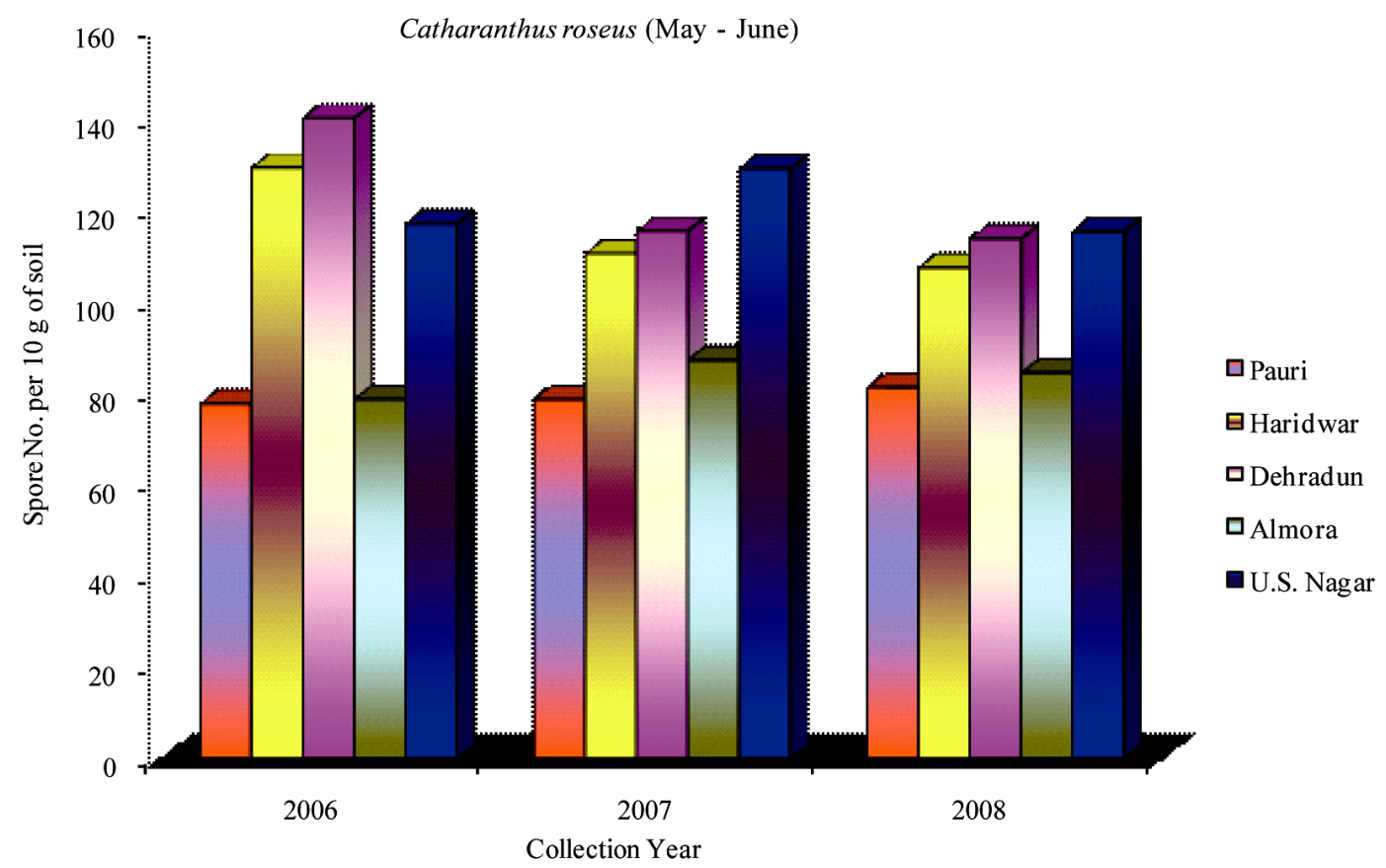

Figure 2. Average number of VAM fungal spores isolated from the soil samples of Catharanthus roseus from different districts in Uttarakhand state during the months of May and June from year 2006 to 2008.

showed maximum population followed by Glomus geosporum, Glomus mosseae, Gigaspora margarita and Sclerocystis sinuosa. Sites F, G and H showed higher number of spore population in Jan-Feb. During the month of May-June and Sep-Oct, no significant variation in spore number was recorded. The spore population at sites
$\mathrm{B}, \mathrm{C}$ and $\mathrm{K}$ showed an interesting variation in spore number. In sharp contrast to observations made generally at other sites, the number of spores at these sites (B, C and $\mathrm{K}$ ) slightly increased during the month of May-June, whereas the number decreased in Jan-Feb and further slightly increased in Sep-Oct. 


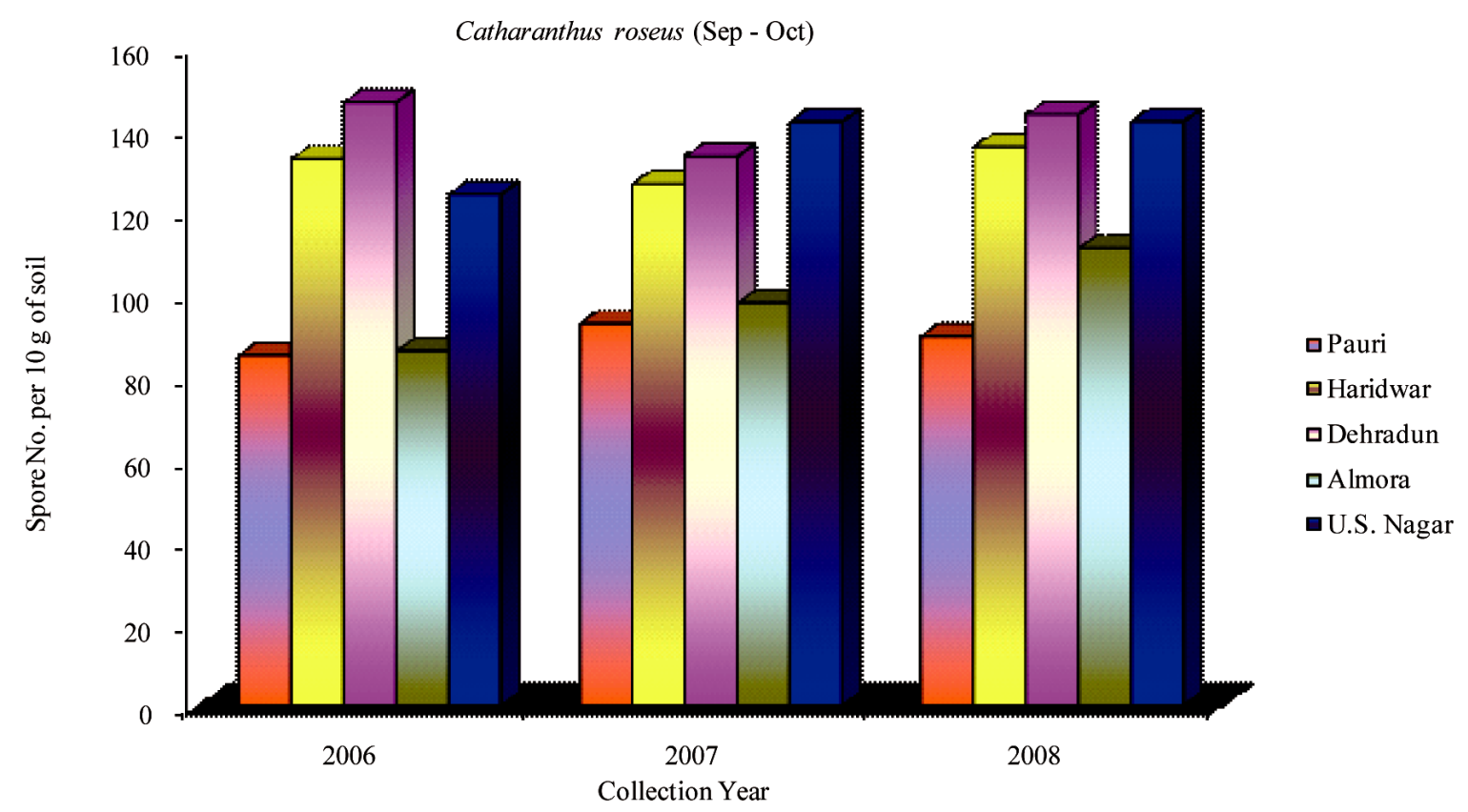

Figure 3. Average number of VAM fungal spores isolated from the soil samples of Catharanthus roseus from different districts in Uttarakhand state during the months of September and October from year 2006 to 2008.

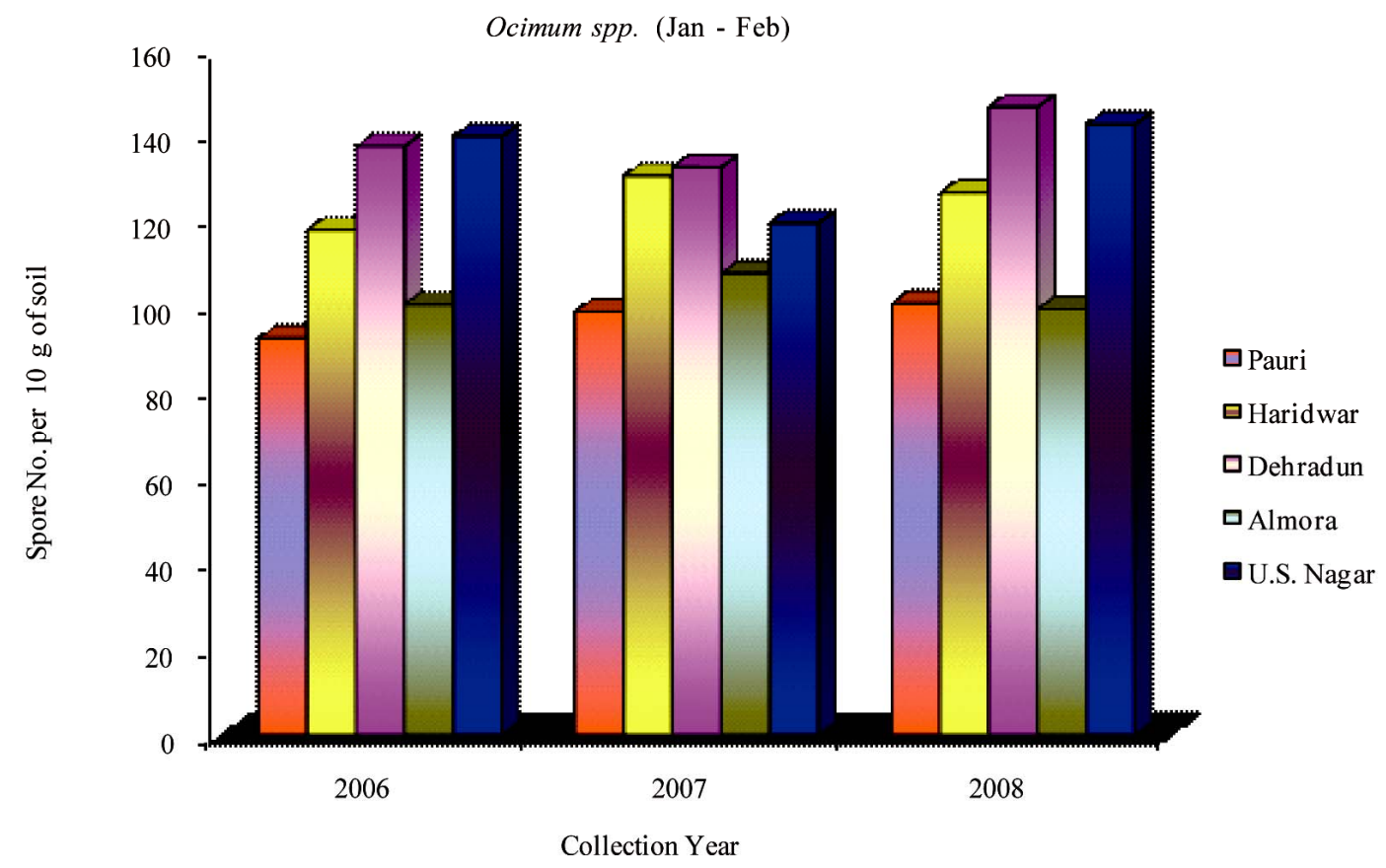

Figure 4. Average number of VAM fungal spores isolated from the soil samples of Ocimum spp. from different districts in Uttarakhand state during the months of January and February from year 2006 to 2008.

The maximum number of VAM spores in Asparagus racemosus was found at sites $\mathrm{F}, \mathrm{H}, \mathrm{A}$ and $\mathrm{K}$. Spores of Glomus fasciculatum, Glomus etunicatum and Glomus mosseae were isolated from these sites as dominant spore population. The spores of Gigaspora margarita and Acaulaspora scrobiculata were also observed. The spore number at $\mathrm{F}$ and $\mathrm{H}$ sites were low during May-June but increased in Sep-Oct and Jan-Feb. However, at A and K sites the spore count increased in May-June in comparison to Jan-Feb. Maximum number of spores were isolated during the month of Sep-Oct. Minimum number of spores were found at site $\mathrm{C}$ due to high altitude and 


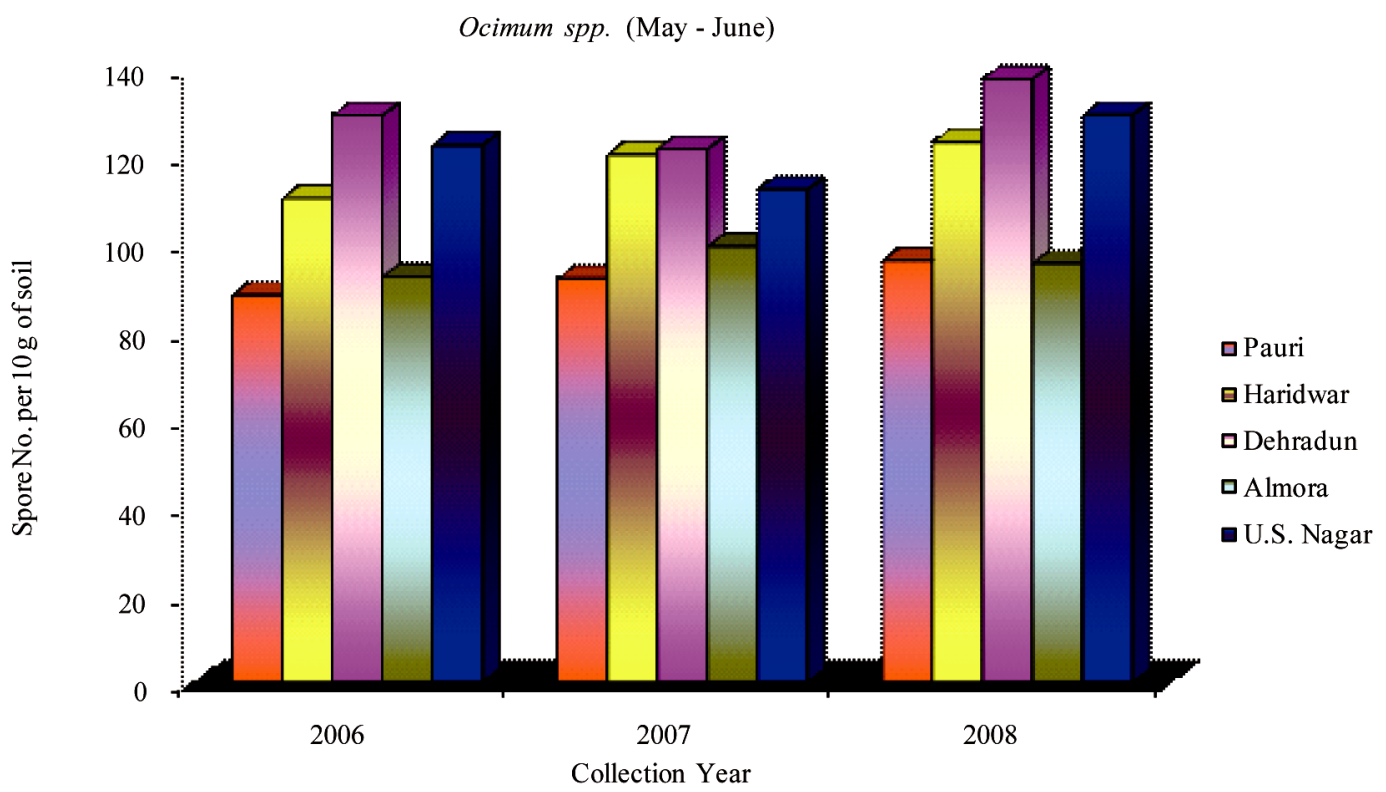

Figure 5. Average number of VAM fungal spores isolated from the soil samples of Ocimum spp. from different districts in Uttarakhand state during the months of May and June from year 2006 to 2008.

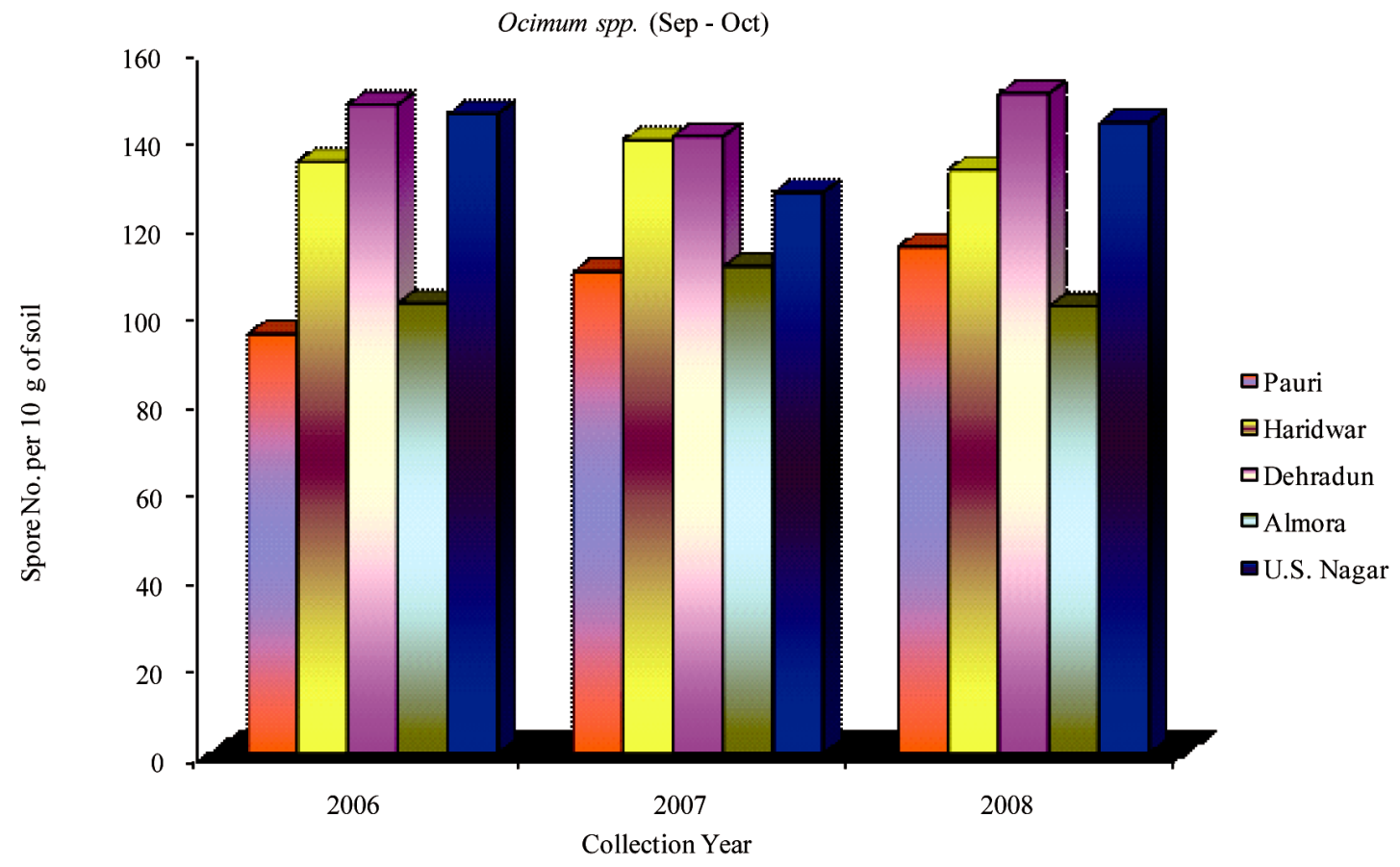

Figure 6. Average number of VAM fungal spores isolated from the soil samples of Ocimum spp. from different districts in Uttarakhand state during the months of September and October from year 2006 to 2008.

unfavourable conditions.

\section{Discussion}

Most of the study showed that host plant had much more effect on spore population. Number of spores also varied with the growing season of the host plant. The studies carried out indicated the maximum spore abundance at the end of growing season. This analysis was performed collectively and individually on all medicinal plants. Hayman [16] reported increase in spore densities during summer season and decline in autumn. But, during the present study most of the sites showed a general increase in spore number from Sep-Oct to Jan-Feb. During all 


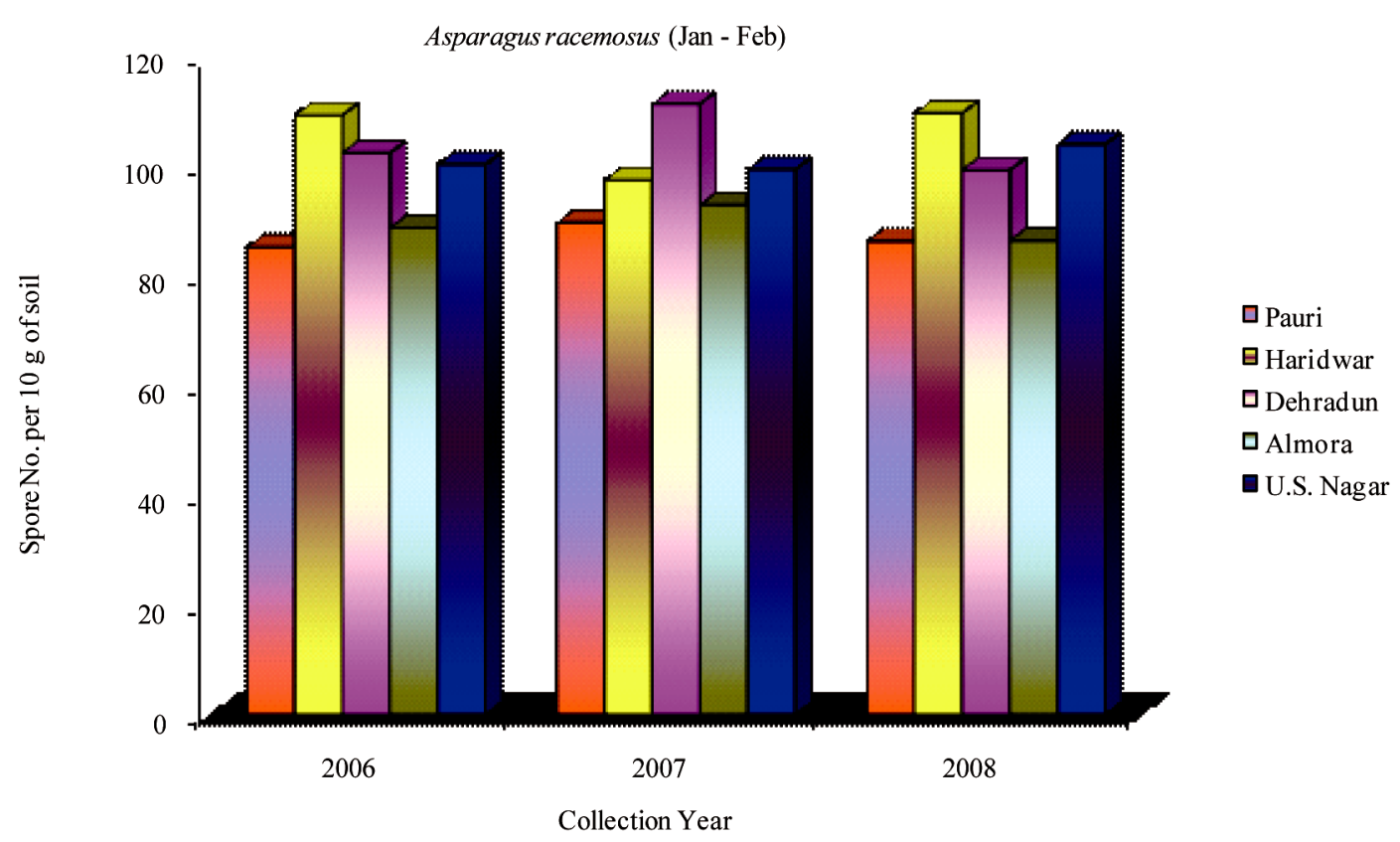

Figure 7. Average number of VAM fungal spores isolated from the soil samples of Asparagus racemosus from different districts in Uttarakhand state during the months of January and February from year 2006 to 2008.

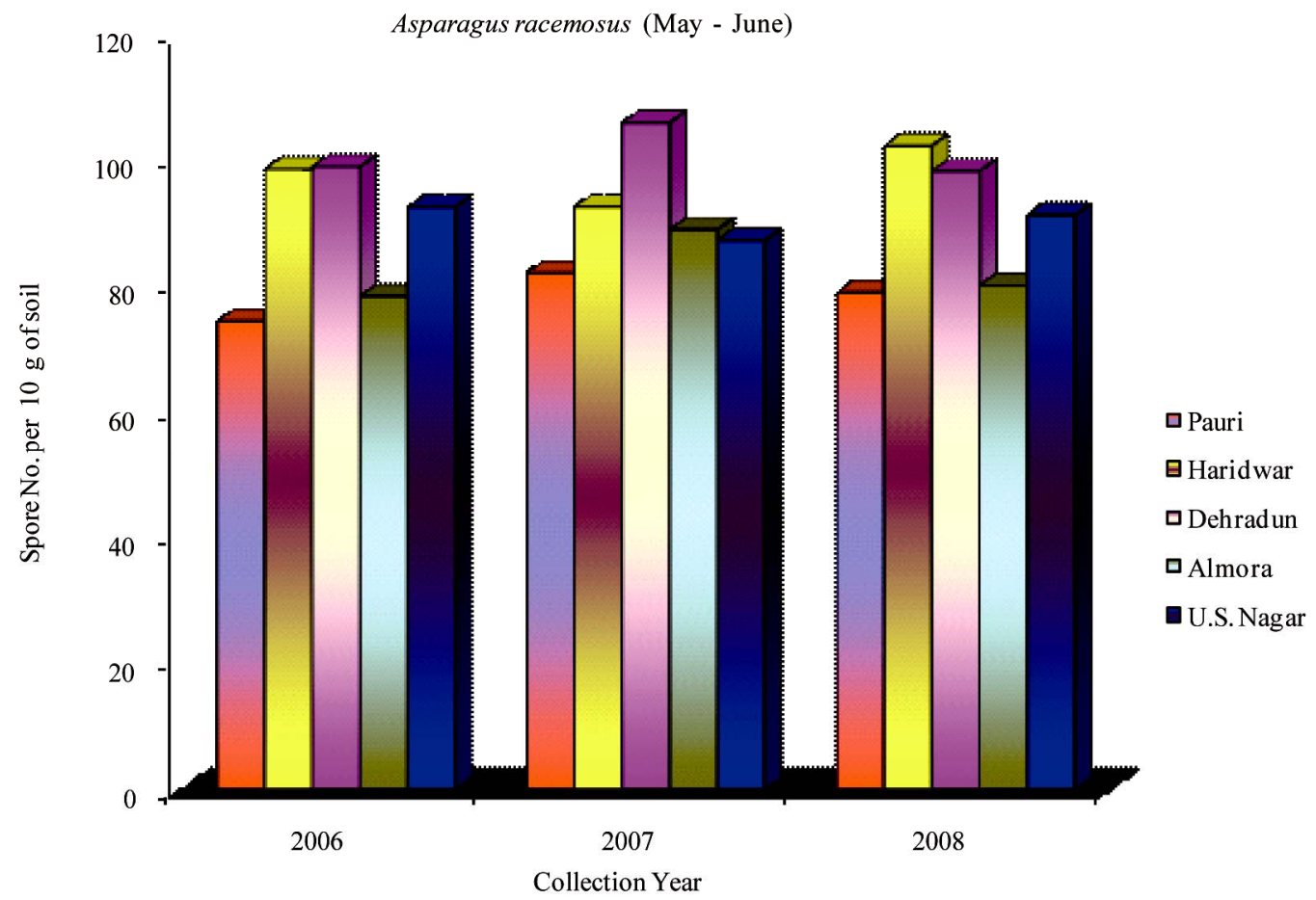

Figure 8. Average number of VAM fungal spores isolated from the soil samples of Asparagus racemosus from different districts in Uttarakhand state during the months of May and June from year 2006 to 2008.

seasons, the most abundant endophyte recorded was Glomus fasciculatum, followed by Glomus aggregatum, Glomus macrocarpum and Glomus mosseae. Species of Acaulospora and Sclerocystis were isolated from different soil types of Uttarakhand region, but were never recorded as a dominant species.

The mean temperature in the month of Jan-Feb, MayJune and Sep-Oct ranges around $6^{\circ} \mathrm{C}-22^{\circ} \mathrm{C}, 25^{\circ} \mathrm{C}-40^{\circ} \mathrm{C}$ and $20^{\circ} \mathrm{C}-25^{\circ} \mathrm{C}$ respectively. The monthly and seasonal temperature varied and had considerable effect on VAM 


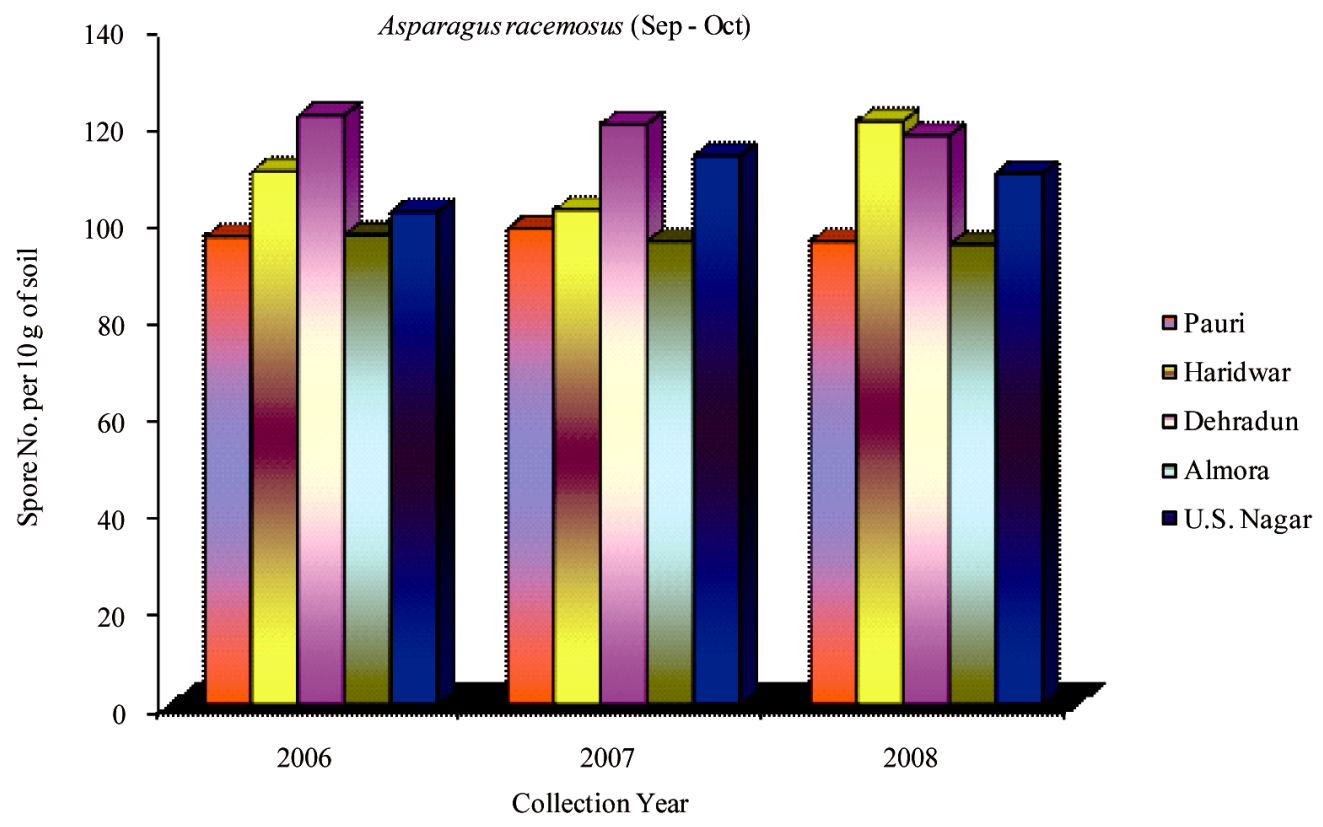

Figure 9. Average number of VAM fungal spores isolated from the soil samples of Asparagus racemosus from different districts in Uttarakhand state during the months of September and October from year 2006 to 2008.

fungal population. Thus temperature seems to be a noteworthy factor in the distribution of VAM fungus propagules. The higher temperature in the month of MayJune reduces the spore population, but the month of JanFeb and Sep-Oct favours VAM spore population. Similar observations were recorded for moisture and humidity also. Higher humidity and moisture content reduces spore count.

Maximum species diversity was observed for habitats I and $\mathrm{M}$. The highest numbers of soil samples were collected from site I (i.e. 50). The minimum mean species diversity was found at site E. Few sites did not show the existence of VAM fungi in all the samples collected. These habitats had all types of soil i.e. loam, sandy loam and clay.

The study reflected a trend indicating decrease in the richness and diversity of vesicular arbuscular mycorrhizal fungi with the increasing altitude. It coincides with the fact that the flora richness and diversity also decreases with increase in geographical altitude. Very few VAM spores were found from the soil sample of Kyunkaleshwar due to high altitude

The medicinal plant roots of natural as well as cultivated plants were found to be heavily colonized by VAM fungi during the period of active growth. Mycorrhizal colonization was more frequent in forest areas than in the cultivated fields. It is likely that fertilizer application to cultivated land reduces VAM species [17].

Present research revealed more abundance of VAM fungal spores in cultivated soils than non-cultivated soils.
Maximum numbers of spores were isolated from undisturbed natural vegetation sites, followed by cultivated and lastly non-cultivated and barren areas. The potential reason for maximum number of spores availability in undisturbed natural vegetation is that spores keep multiplying in association with plants and remain in soil for isolation later on. Whereas, in cultivated habitat the top soil is disturbed each time as some fresh crop is sown.

\section{Conclusion}

Based on the richness of medicinal plants in Uttarakhand state, the present research work considered three medicinal plants which are Asparagus racemosus, Catharanthus roseus and Ocimum spp. On the basis of study carried out it can be concluded that the VAM fungi are well distributed throughout various region of the state. To account for seasonal variations, soil and root samples were collected in months of Jan-Feb, May-June and Sep-Oct from year 2006 to 2008. All the medicinal plants studied exhibited association with VA mycorrhizal fungi. Undistributed natural vegetation of these medicinal plants showed maximum number of spores in comparison to the cultivated ones. VAM spores were found in higher abundance from sandy loam soils followed by clay and loam soils. The number of spores was minimum at higher altitude. An inference was made out clearly that Ocimum spp. had highest levels of mycorrhizal root colonization percentage. The seasonal temperature variations had considerable effect on VAM fungal population. Temperature can be surely considered as an important factor in the 
distribution of VAM fungus propagules. The higher temperature in the month of May-June reduced the spore population, but the month of Jan-Feb and Sep-Oct favoured VAM spore population. Similar observations were recorded for moisture and humidity also. Higher humidity and moisture content reduced spore count.

\section{REFERENCES}

[1] P. Kaushik, “Introductory Microbiology,” Emkay Publication, New Delhi.

[2] N. Mathur and A. Vyas, "Arbuscular Mycorrhiza on RootOrgan Cultures,” American Journal of Plant Physiology, Vol. 2, No. 2, 2007, pp. 122-138. doi:10.3923/ajpp.2007.122.138

[3] P. Kaushik and A. K. Dhiman, "Medicinal Plants and Raw Drugs of India,” Bishen Singh Mahendra Pal Singh, Dehradun, 2000.

http://www.vedicbooks.net/medicinal-plants-and-raw-dru gs-of-india-p-13886.html

[4] P. P. Joy, J. Thomas, S. Mathew and B. P. Skaria, "Medicinal Plants,” In: T. K. Bose, J. Kabir, P. Das and P. P. Joy, Eds., Tropical Horticulture, Naya Prokash, Calcutta, 2001, pp. 449-632.

[5] A. K. Tiwari, “Ayurveda Will Survive till Bharat Breathes," Current Science, Vol. 90, No. 12, 2006, pp. 1589-1590. http://www.ias.ac.in/currsci/jun252006/1589a.pdf

[6] S. R. Saif, "Soil Temperature, Soil Oxygen and Growth of Mycorrhizal and Non-Mycorrhizal Plants of Eupatorium odoratum L. and Development of Glomus macrocarpus,” Angewandte Botanik, Vol. 57, 1983, pp. 143-155.

[7] Y. Matsubara and H. Harada, "Effect of Constant and Diurnally Fluctuating Temperatures on Arbuscular Mycorrhizal Fungus Infection and Growth of Infected Asparagus (Asparagus officinalis L.) Seedlings,” Journal of the Japanese Society for Horticultural Science, Vol. 65, No. 3, 1996, pp. 565-570. doi:10.2503/jjshs.65.565

[8] P. G. Braunberger, L. K. Abbott and A. D. Robson, "Early
Vesicular-Arbuscular Mycorrhizal Colonization in Soil Collected from an Annual Clover-Based Pasture in a Mediterranean Environment: Soil Temperature and Timing of Autumn Rains," Australian Journal of Agricultural Research, Vol. 48, No. 1, 1997, pp. 103-110. doi:10.1071/A96049

[9] J. M. Phillips and D. S. Hayman, "Improved Procedures for Clearing Roots and Staining Parasitic and VesicularArbuscular Mycorrhizal Fungi for Rapid Assessment of Infection," Transactions of the British Mycological, Vol. 5, No. 1, 1970, pp. 158-161. doi:10.1016/S0007-1536(70)80110-3

[10] I. R. Hall and B. J. Fish, "A Key to the Endogonaceae," Transactions of the British Mycological, Vol. 73, No. 2, 1978, pp. 261-270. doi:10.1016/S0007-1536(79)80110-2

[11] I. R. Hall, “Taxonomy of VAMycorrhizal Fungi,” In: C. L. Powell and D. J. Bagyaraj, Eds., VA Mycorrhiza, CRC Press, Boca Raton, 1984, pp. 57-94.

[12] I. R. Hall, "Taxonomy and Identification of Vesicular Arbuscular Mycorrhizal Fungi,” Journal of Applied Botany, Vol. 61, 1987, pp. 145-152.

[13] J. W. Gerdemann and J. M. Trappe, "The Endogonaceae of the Pacific Northwest,” Mycologia Memoirs, Vol. 5, 1974, p. 76.

[14] N. C. Schenck and Y. Perez, "Manual for the Identification of VA Mycorrhizal Fungi,” Synergistic Publications, University of Florida, Gainesville, 1989.

[15] S. C. Pandya, G. S. Puri and J. S. Singh, "Research Methods in Plant Ecology,” Asia Publication House, Bombay, 1968.

[16] D. S. Hayman, "Endogone Spore Numbers in Soil and Vesicular-Arbuscular Mycorrhiza in Wheat as Influenced by Season and Soil Treatment," Transactions of the British Mycological Society, Vol. 54, No. 1, 1970, pp. 53-63. doi:10.1016/S0007-1536(70)80123-1

[17] B. Mosse and D. S. Hayman, "Mycorrhiza in Agricultural Plants,” In: P. Mikola, Ed., Tropical Mycorrhiza Research, Clarendon Press, Oxford, 1980, pp. 213-230. 